\title{
The influence of powder properties on the adhesion strength and microstructural evolution of cold sprayed Ti6Al4V single splats
}

\author{
Venkata Naga Vamsi Munagala, Sara I. Imbriglio and Richard. R. Chromik* \\ Department of Mining and Materials Engineering, McGill University, Montreal, QC H3A 0C5, \\ Canada
}

\begin{abstract}
The adhesion strength and microstructure of single splats significantly influence the properties of cold sprayed coatings. Here, we compare the adhesion strength and microstructural changes of Ti6Al4V spherical powder (SP) particles with a martensitic microstructure and irregular powder (IP) particles with an equiaxed microstructure deposited by cold spray (CS). Splat adhesion tests were performed to determine the adhesion strength and electron channelling contrast imaging was done for microstructural analysis of splat cross-sections. IP splats formed a continuous bonded interface with the substrate resulting in a greater adhesion strength when compared to SP splats. IP splat cross-sections revealed ultrafine grains (UFG) near the interface followed by a highly deformed microstructure. SP splat cross-sections also showed UFG at the interface but largely retained the initial microstructure in the top portion of the splat due to poor deformability. The irregular morphology of the IP led to more adherent deposits while the equiaxed microstructure resulted in highly deformed post spray microstructures.
\end{abstract}

Keywords: Adhesion; Cold spray; Microstructure; Ti6Al4V; Armstrong powders; single splats

\section{Introduction}

The cold spray (CS) process involves the acceleration of powder particles to supersonic velocities for impact onto a substrate resulting in coating buildup [1,2]. The process is widely used for the repair of worn aerospace, automobile and marine components made of Ti and its alloys, due to its versatility and ability to deposit powder particles in solid state [3]. However, Ti6A14V coatings deposited using plasma gas atomized (PGA) powder have high porosity. Techniques to reduce porosity include spraying with $\mathrm{He}$, using mechanically blended powders or in situ shot peening 
assisted deposition [4-7]. These techniques are either complex, non-sustainable or non-economical for industrial applications.

Since coating formation relies on deformation of powder particles to form a splat, microstructural changes in splats and adhesion in splat interfaces or splat-substrate interfaces largely affect coating properties [1]. Adhesion strength measurements and microstructural analysis at splat level forms a fundamental approach to understand the bulk coating characteristics [8-13]. Post spray microstructure and adhesion strength of Ti6Al4V splats deposited using PGA powders have been studied extensively $[9,10,14]$. Scanning electron microscope (SEM) and transmission electron microscope images of splat cross-sections have shown that deformation and recrystallization occurs only at the splat-substrate interface while the bulk of the particle retains its initial microstructure $[8,10,15]$. The low deformability of these powders results in poor bonding between the splats and porosity in the bulk coatings.

Recently, $\mathrm{Ti}$ and $\mathrm{Ti6A14V}$ powders with irregular morphology were manufactured using an Armstrong process, which is more economical compared to the PGA process [16,17]. Cold spraying these powders produces deposits that are more dense than deposits made with PGA powders [16,18]. In our previous study [18], the cohesive strength of coatings made with PGA and Armstrong powders was evaluated by multi-scale indentation. The improvements of decreased porosity and increased cohesive strength for coatings made from Armstrong powders were tied to increased in-flight particle velocity, due to irregular morphology, and deformability, due to particle microstructure. However, the relative importance of these two factors could not be fully determined in the previous work [18]. In the present study, to better understand the candidate mechanisms for improved deposition with Armstrong powder versus PGA powders, the adhesion and microstructural transformations are studied for single irregular powder (IP) and PGA Ti6A14V particles sprayed onto Ti6A14V substrates at similar spray conditions and particle velocities. Splat adhesion testing [12] was done to determine the adhesion strength and electron channelling contrast imaging (ECCI) was performed on the splat cross-sections to characterize the post spray microstructures.

\section{Experimental}

Single splats were deposited on Ti6A14V substrates (McMaster Carr, Canada) using a PCS 1000 cold spray system (Plasma Giken, Japan) with nitrogen as the propellent gas. Ti6A14V (Grade 5) 
powders with a spherical morphology (average diameter $\sim 31 \mu \mathrm{m}$ ), manufactured using PGA, and irregular morphology (average diameter $\sim 38 \mu \mathrm{m}$ ), manufactured using the Armstrong process, were used for depositing splats. The size distribution and detailed characterization of the powder particles are presented elsewhere [17]. For depositing splats using spherical powders, the gas pressure and temperature were fixed at $4.9 \mathrm{MPa}$ and $950^{\circ} \mathrm{C}$ whereas the IP splats were sprayed at two different temperatures, $600^{\circ} \mathrm{C}$ and $950^{\circ} \mathrm{C}$ respectively, keeping the pressure constant at 4.9 $\mathrm{MPa}$. The gun transverse speed was $1 \mathrm{~m} \cdot \mathrm{s}^{-1}$ and the in-flight particle velocity was measured using a time-of-flight particle diagnosis system (Coldspraymeter, Tecnar Automation, Canada).

After deposition, the samples were cut and polished using SiC abrasive papers up to a grit size of 1200 and subsequently with diamond suspension solution of $9 \mu \mathrm{m}, 3 \mu \mathrm{m}, 1 \mu \mathrm{m}$ and finally using $0.05 \mu \mathrm{m}$ colloidal suspension. Polished IP splat cross-sections were ion-milled using a IM300 flat milling system (Hitachi High-Technologies, Japan) to remove edge rounding induced by polishing. To observe the splat microstructure, ECCI was performed using a cold field emission SEM (SU8230, Hitachi, Japan) equipped with a photo-diode back scattered electron detector.

Adhesion strength of single splats was measured using a Micro-Combi scratch tester (CSM Instruments, USA) to perform splat adhesion testing [12]. A semi-circular tipped stylus of diameter $100 \mu \mathrm{m}$ was mounted on the scratch tester and the flat edge of the tip was used to scratch the splats off the substrate. Prior to testing, an optical image of the splat was captured using a light optical microscope attached to the scratch tester. For all the tests, the scratch length, speed and normal force (on the tip) were $100 \mu \mathrm{m}, 150 \mu \mathrm{m} \cdot \mathrm{min}^{-1}$, and $100 \mathrm{mN}$, respectively. During the entire test, the tangential force experienced by the stylus was continuously recorded. As the stylus encountered the splat, a rise in tangential force ( $\mathrm{F}_{\mathrm{T}}$ Peak $)$ was observed followed by a sudden drop at interface failure ( $\mathrm{F}_{\mathrm{T}}$ Baseline). This data was used to determine the adhesion strength in shear i.e. in parallel to the splat-substrate interface using Eq. 1. [12]. At least 15 splats were tested to determine the average adhesion strength.

$$
\text { Adhesion strength }(M P a)=\frac{F_{T \text { Peak }}(m N)-F_{T \text { Baseline }}(m N)}{\text { Projected area of the splat }\left(\mu m^{2}\right)}
$$

\section{Results and discussion}

The particle velocity and the adhesion strength of the splats are summarized in Table 1 . At the same spray conditions (Table 1), the higher velocity of IP particles compared to spherical powder 
(SP) particles was due to the higher drag force acting on them $[18,19]$. The adhesion strength of IP splats was higher compared to SP splats at the same spray conditions as confirmed by an independent samples t-test (i.e. student's t-test). However, at more similar particles velocities, their adhesion strength was not different. In the t-test, the null hypothesis was rejected if the $p$ value was less than 0.05 . The higher adhesion strength of IP splats, at identical spray conditions, was due to the irregular shape that lead to higher particle velocities. For Ti6A14V, Goldbaum et al. showed that higher velocities leads to more conformal bonding and higher splat adhesion strength. [9]

For Armstrong powders, the irregular surface morphology enables the particles to have a large number of localized contact points and greater strain localization during particle impact [20]. This results in localized jetting. The localized jetting can be seen in the side view images of the splat (see Fig. $1 \mathrm{~b}$ and c). Contrarily, jetting along the entire periphery was observed from the top view in SP splat (Fig. 1a). This is a general characteristic of cold sprayed SP particle $[2,10]$.

Table 1. Particle velocity and adhesion strength of the splats

\begin{tabular}{lcccc}
\hline Powder & $\begin{array}{c}\text { Gas pressure } \\
(\mathbf{M P a})\end{array}$ & $\begin{array}{c}\text { Gas temperature } \\
\left(\mathbf{(}^{\circ} \mathbf{C}\right)\end{array}$ & $\begin{array}{c}\text { Particle velocity } \\
\left(\mathbf{m} \cdot \mathbf{s}^{-\mathbf{1}}\right)\end{array}$ & $\begin{array}{c}\text { Adhesion } \\
\text { strength (MPa) }\end{array}$ \\
\hline Spherical & 4.9 & 950 & $782 \pm 152$ & $107 \pm 53$ \\
Irregular & 4.9 & 950 & $865 \pm 174$ & $153 \pm 48$ \\
Irregular & 4.9 & 600 & $752 \pm 135$ & $109 \pm 51$ \\
\hline
\end{tabular}
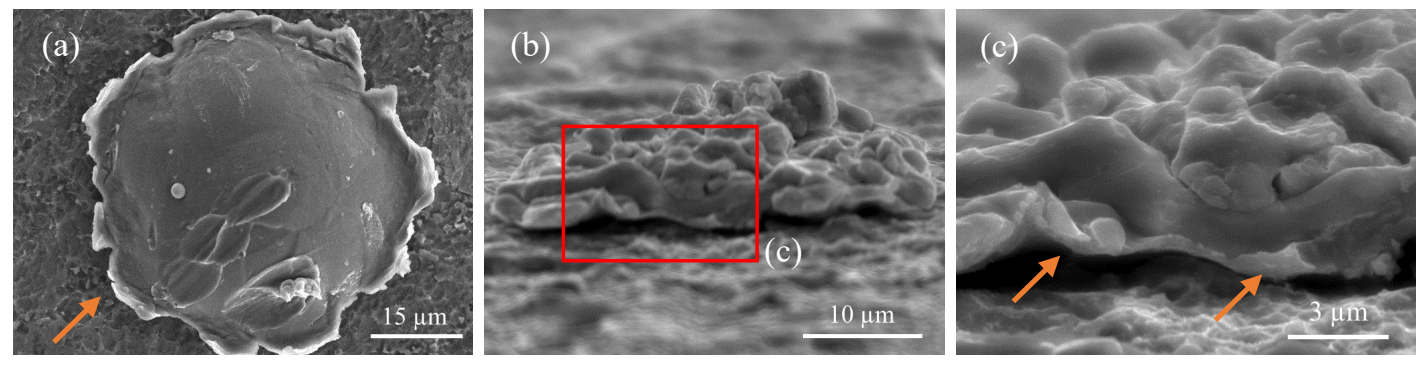

Fig. 1. SEM images of the splats deposited at $4.9 \mathrm{MPa}$ and $950{ }^{\circ} \mathrm{C}$ (a) Top view of the SP splat (b) side view of the IP splat (c) higher magnification image of IP splat; Arrow indicates jetting. 
Cross-sectional splat morphology also appeared to be significantly different for both powders (Figs. 2 and 3). SP splat cross-sections showed discontinuous bonding at the splat-substrate interface with very few bonded sites (Fig. 2b). IP splat showed more continuous bonding with a few interface voids (Fig 3b). As SP particles impact, the centre experiences the highest hydrostatic pressure leading to rebound and void formation $[2,10]$. Adiabatic shear instabilities at the outer edges result in bonding. $[1,10]$ The formation of void at the centre of the spat-particle interface in SP splat can be seen in Fig. $2 b$.

The microstructural changes occurring after impact were studied by comparing splat crosssectional microstructure and initial powder microstructures in ECCI images. Initially, SP had a martensitic lath microstructure (Fig. 2a) while IP had an equiaxed microstructure (Fig. 3a). SP splat cross-sections revealed three regions of different microstructures whereas IP splat crosssections showed two distinct microstructures. At the interface, both SP and IP splats had ultra-fine grains (UFG). Yet, the height of the UFG region differed for IP and SP splats (Fig. 2e and 3e). In SP splat, UFG were seen up to a distance of $\sim 3 \mu \mathrm{m}$ from the splat-substrate interface (Fig. 2e), followed by elongated submicron grains (Fig. 2d) and finally a retained martensitic lath microstructure at the top surface (Fig. 2c). The formation of submicron grains was due to the reorientation of an accumulated high density of dislocations during severe plastic deformation while UFG were formed due to the progressive deformation of the particle after the creation of submicron grains $[10,13]$. Thus, UFG were mainly observed near the splat-substrate interface where particles experience high strain rates resulting in continuous dynamic recrystallization. Contrarily, in IP splats, UFG were seen up to a distance of $\sim 4.5 \mu \mathrm{m}$ (Fig. $3 \mathrm{~d}$ and $3 \mathrm{e}$ ) followed by a heavily deformed microstructure up to the top surface of the splat (Fig. 3d and 3c). The initial microstructure was not completely retained due to the deformable equiaxed microstructure of IP in contrast to the hard martensitic lath microstructure of SP. The advantages of using these irregular powders for CS of Ti6Al4V are consistent with previous observation in full coatings. IP coatings had negligible porosity and better cohesive strength between splats compared to SP coatings [18].

Substrates also had evidence of deformation in their microstructure. Near the particle-substrate interface, substrates had recrystallized UFG. Further away from the interface, highly deformed grains were observed. The formation of UFG in the substrate for SP and IP splats can be seen in Figs. $2 \mathrm{f}$ and $3 \mathrm{e}$. A more continuous layer of UFG was observed in the substrate of IP splats 
compared to SP splats which could be due to the higher impact velocity and localized contact points of impact of the IP.
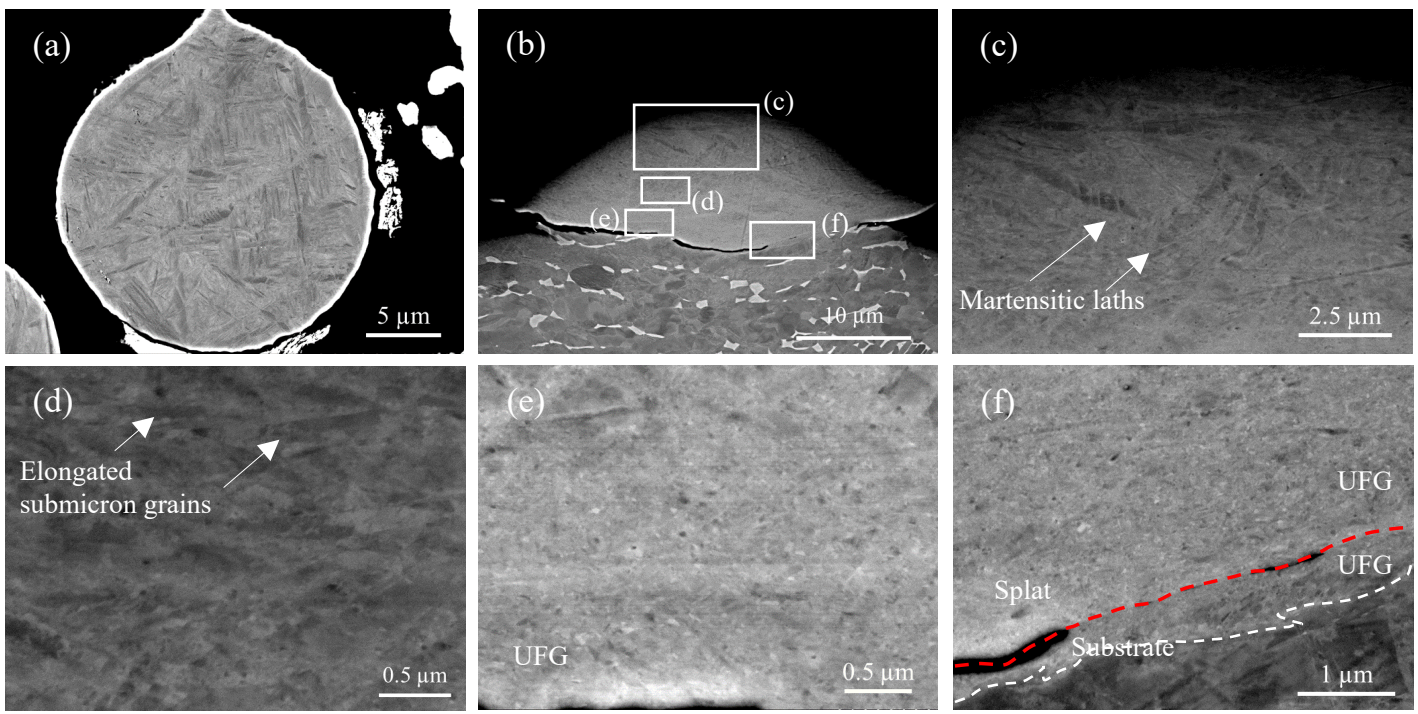

Fig. 2. ECCI of SP (a) particle (b) splat deposited at $4.9 \mathrm{MPa}$ and $950{ }^{\circ} \mathrm{C}$ (c) top region of the splat (d) middle region showing sub micron grains (e) UFG region at the splat-substrate interface (f) splat-substrate bonded interface; Red dashed line indicates splat-substrate interface and white dashed line indicates the UFG and highly deformed region interface in the substrate.
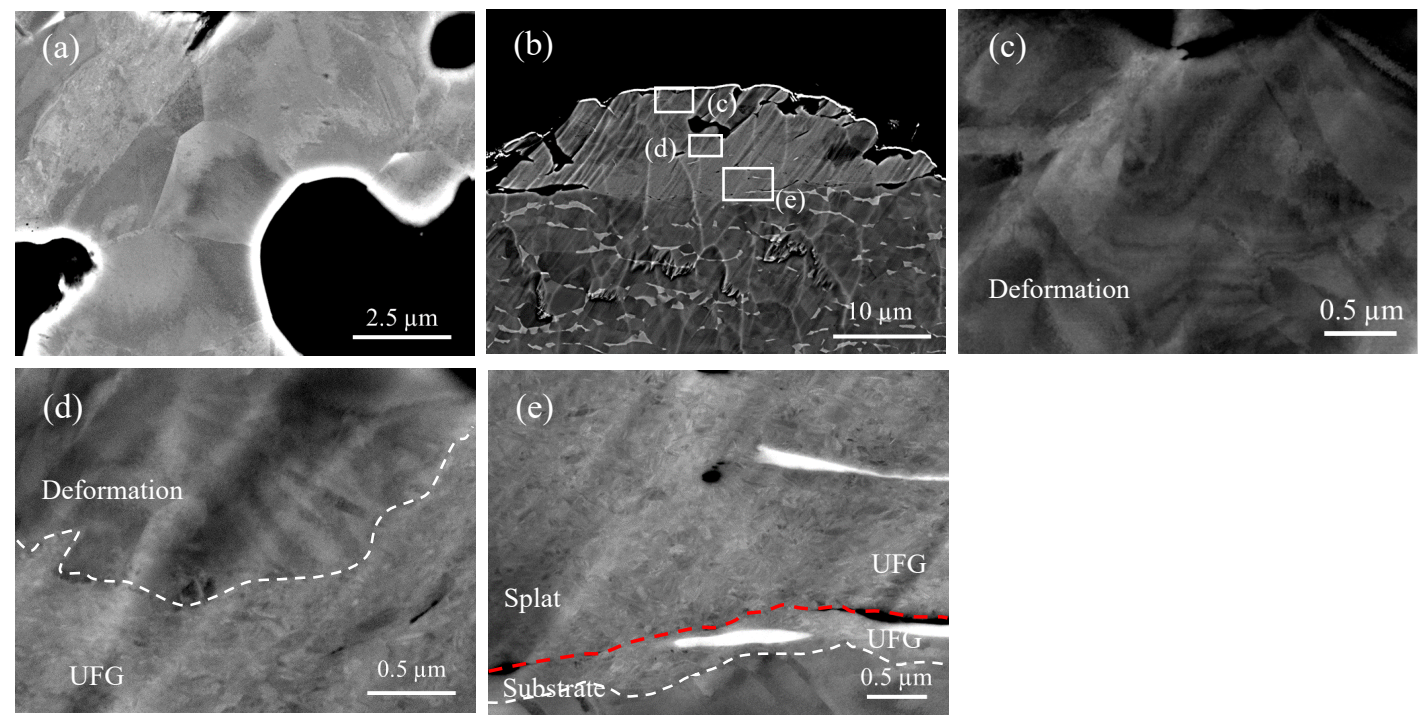

Fig. 3. ECCI of IP (a) particle (b) splat deposited at $4.9 \mathrm{MPa}$ and $950{ }^{\circ} \mathrm{C}$ (c) top region of the splat (d) middle region showing UFG + deformation (e) bottom of the splat and splatsubstrate bonded interface. Red dashed line indicates splat-substrate interface and white dashed line indicates the UFG and highly deformed region interface in the substrate. 


\section{Conclusions}

Splat adhesion tests along with ECCI of splat cross-sections helped to understand the adhesion strength and microstructural changes that occur in both powders. IP splats showed higher adhesion strength than SP splats. This was due to their irregular morphology that accelerates them to higher velocities at similar spray conditions. However, when sprayed at the same particle velocity, the IP splats did not show an improvement in adhesion strength compared to SP splats. These results indicate that particle velocity has more profound effect on the adhesion strength rather than microstructure. ECCI of the splat cross-sections showed greater extent of grain refinement and microstructure transformations in IP compared to SP indicating their high deformability. Lastly, for IP, when sprayed at lower gas temperatures to attain similar particle velocities as SP, both splats showed similar adhesion strength. This indicates that Armstrong manufactured irregular powders can be used to deposit Ti6Al4V coatings on to heat sensitive components with adhesion strength comparable to that of PGA powders.

\section{Acknowledgements}

The authors are thankful for the technical assistance from Maniya Aghasibeig and Jean-Francois Alarie at McGill Aerospace Materials and Alloy Design Centre (MAMADC). The authors gratefully acknowledge the contributions of Rene Cooper from Cristal Metals for providing the irregular Ti6Al4V powders.

\section{References}

[1] T. Schmidt, H. Assadi, F. Gärtner, H. Richter, T. Stoltenhoff, H. Kreye, T. Klassen, From particle acceleration to impact and bonding in cold spraying, J. Therm. Spray Technol. 18 (2009) 794-808.

[2] H. Assadi, H. Kreye, F. Gärtner, T. Klassen, Cold spraying - A materials perspective, Acta Mater. 116 (2016) 382-407.

[3] P. Vo, D. Goldbaum, W. Wong, E. Irissou, J. Legoux, R.R. Chromik, S. Yue, Cold-spray processing of titanium and titanium alloys, in: Titan. Powder Metall., Elsevier Inc., 2015: pp. 405-424.

[4] X.T. Luo, Y.K. Wei, Y. Wang, C.J. Li, Microstructure and mechanical property of Ti and Ti6A14V prepared by an in-situ shot peening assisted cold spraying, Mater. Des. 85 (2015) 527-533.

[5] P. Vo, E. Irissou, J. Legoux, S. Yue, Mechanical and Microstructural Characterization of Cold-Sprayed Ti-6Al-4V After Heat Treatment, 22 (2013) 954-964.

[6] H. Aydin, M. Alomair, W. Wong, P. Vo, Cold sprayability of mixed commercial purity Ti 
plus Ti6Al4V metal powders, J. Therm. Spray Technol. 26 (2017) 360-370.

[7] V.S. Bhattiprolu, K.W. Johnson, O.C. Ozdemir, G.A. Crawford, Influence of feedstock powder and cold spray processing parameters on microstructure and mechanical properties of Ti-6Al-4V cold spray depositions, Surf. Coatings Technol. 335 (2018) 1-12.

[8] D. Goldbaum, R.R. Chromik, N. Brodusch, R. Gauvin, b, Microsc. Microanal. 21 (2015) 570-581.

[9] D. Goldbaum, J.M. Shockley, R.R. Chromik, A. Rezaeian, S. Yue, J.G. Legoux, E. Irissou, The effect of deposition conditions on adhesion strength of Ti and Ti6Al4V cold spray splats, J. Therm. Spray Technol. 21 (2012) 288-303.

[10] J. Yan Lek, A. Bhowmik, A. Wei-Yee Tan, W. Sun, X. Song, W. Zhai, P.J. Buenconsejo, F. Li, E. Liu, Y. Ming Lam, C.B. Boothroyd, Understanding the Microstructural Evolution of Cold Sprayed Ti-6Al-4V Coatings on Ti-6Al-4V Substrates, Appl. Surf. Sci. 459 (2018) 492-504.

[11] D. MacDonald, A. Nastik, B. Jodoin, Understanding Adhesion, in: Cold-Spray Coatings Recent Trends Futur. Perspect., 2018: pp. 421-451.

[12] R.R. Chromik, D. Goldbaum, J.M. Shockley, S. Yue, E. Irissou, J.G. Legoux, N.X. Randall, Modified ball bond shear test for determination of adhesion strength of cold spray splats, Surf. Coatings Technol. 205 (2010) 1409-1414.

[13] M.R. Rokni, S.R. Nutt, C.A. Widener, V.K. Champagne, R.H. Hrabe, Review of Relationship Between Particle Deformation, Coating Microstructure, and Properties in High-Pressure Cold Spray, J. Therm. Spray Technol. 26 (2017) 1308-1355.

[14] M.V. Vidaller, A. List, F. Gaertner, T. Klassen, S. Dosta, J.M. Guilemany, Single Impact Bonding of Cold Sprayed Ti-6Al-4V Powders on Different Substrates, J. Therm. Spray Technol. 24 (2015) 644-658.

[15] A.M. Birt, V.K. Champagne, R.D. Sisson, D. Apelian, Microstructural Analysis of ColdSprayed Ti-6Al-4V at the Micro- and Nano-Scale, J. Therm. Spray Technol. 24 (2015) 1277-1288.

[16] D. MacDonald, R. Fernandez, F. Delloro, B. Jodoin, Cold Spraying of Armstrong Process Titanium Powder for Additive Manufacturing, J. Therm. Spray Technol. 26 (2017) 598609.

[17] K. Araci, D. Mangabhai, K. Akhtar, Production of titanium by the Armstrong Process ${ }^{\circledR}$, Elsevier Inc., 2015.

[18] V.N.V. Munagala, V. Akinyi, P. Vo, R.R. Chromik, Influence of powder morphology and microstructure on the cold spray and mechanical properties of Ti6Al4V coatings, J. Therm. Spray Technol. 27 (2018) 827-842.

[19] B. Jodoin, L. Ajdelsztajn, E. Sansoucy, A. Zúñiga, P. Richer, E.J. Lavernia, Effect of particle size, morphology, and hardness on cold gas dynamic sprayed aluminum alloy coatings, Surf. Coatings Technol. 201 (2006) 3422-3429.

[20] A. Ganesan, M. Yamada, M. Fukumoto, Cold spray coating deposition mechanism on the thermoplastic and thermosetting polymer substrates, J. Therm. Spray Technol. 22 (2013) $1275-1282$. 